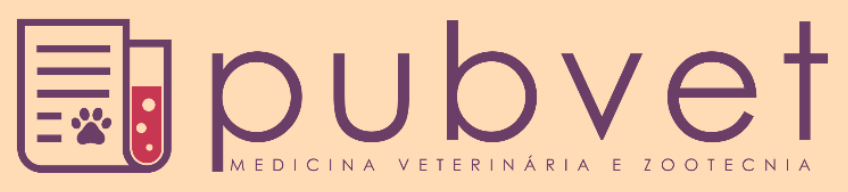

https://doi.org/10.31533/pubvet.v16n01a1009.1-21

\title{
Principais fármacos e vias de administração utilizados em felinos
}

\author{
Cintia Ferreira Antunes de Oliveira ${ }^{1 \bullet} \mathbb{D}$, Emanuely Ramos Tameirão ${ }^{1 \bullet}$, Lucas Wamser Fonseca \\ Gonzaga $^{1 \bullet}$, Luciana de Castro Barcelos ${ }^{1 \oplus}$, Lidiane da Silva Bastos ${ }^{1 \bullet}$, Izabel Cristina Tavares ${ }^{1 \bullet}$, \\ Larissa Alexsandra Felix ${ }^{2} \odot$ (D), João Vitor Fernandes Cotrim de Almeida ${ }^{3} \bullet$, Marcos Ferrante A $^{*} \bullet$ \\ ${ }^{1}$ Graduandos em medicina veterinária pela Universidade Federal de Lavras, departamento de medicina veterinária (UFLA), Lavras-MG, Brasil. \\ ${ }^{2}$ Mestrandas do programa de pós-graduação em ciências veterinárias, UFLA, departamento de medicina veterinária, Lavras-MG, Brasil. \\ ${ }^{3}$ Doutorando do programa de pós-graduação em ciências veterinárias, UFLA, departamento de medicina veterinária, Lavras-MG, Brasil. \\ ${ }^{4}$ Docente do curso de medicina veterinária da Universidade Federal de Lavras, departamento de medicina veterinária, Lavras-MG, Brasil. \\ *Autor para correspondência, E-mail: marcos.ferrante@ufla.br
}

Resumo. Para que os protocolos terapêuticos sejam corretamente instituídos é necessário entender corretamente como serão aplicados. A presente revisão bibliográfica tem como objetivo caracterizar as diferentes vias de administração usadas na Medicina Veterinária felina. Dessa forma, serão abordados diversos exemplos de fármacos utilizados por vias enterais e parenterais. Uma vez que essas particularidades são estudadas, é possível compreender de que maneira cada via atua, fator que aumenta consideravelmente a eficácia dos tratamentos. Em razão da administração de fármacos pelas vias incorretas, bem como da escolha terapêutica na maioria das vezes inapropriada para essa espécie, muitos gatos acabam se intoxicando. Em decorrência da sua deficiência de metabolização hepática e predisposição a desenvolver afecções renais, muitos pacientes têm prognóstico desfavorável e acabam vindo a óbito. Portanto, a fim de evitar possíveis intoxicações por vias de administração incorretas, e melhorar a escolha terapêutica, buscou-se elucidar os diferentes tipos de medicamentos utilizados na espécie felina e formas de administração que podem ser empregadas nesses animais.

Palavras chave: Enterais, medicamentos, medicina felina, parenterais, terapêutica

\section{Main drugs and administration routes used in felines}

\begin{abstract}
For the therapeutic protocols to be properly instituted, it is necessary to correctly understand how they will be applied. This bibliographic review aims to characterize the different administration routes used in feline veterinary medicine. In this way, several examples of drugs used by enteral and parenteral routes will be addressed. Once these particularities are studied, it is possible to understand how each pathway works, a factor that considerably increases the effectiveness of treatments. Due to the administration of drugs through the wrong routes, as well as the therapeutic choice most often inappropriate for this species, many cats end up intoxicating. As a result of their hepatic metabolism deficiency and predisposition to develop kidney disorders, many patients have an unfavourable prognosis and end up dying. For this reason, the objective was to elucidate the different types of drugs used in the feline species, in addition to the different doses and routes of administration that can be used in these animals.
\end{abstract}

Keywords: Enteral, felines, medications, parenteral, routes of administration

\section{Introdução}

Com a antropomorfização dos animais domésticos, muitos tutores passaram a associar medicamentos de uso humano aos tratamentos veterinários. Esse fato, aliado à falta de medicamentos veterinários 
análogos aos de uso humano, leva a uma infinidade de doenças, principalmente devido às diferenças nos seus processos metabólicos e fisiológicos. $\mathrm{O}$ desconhecimento dos fármacos que são permitidos para felinos, juntamente com a via de administração incorreta pode resultar em intoxicações e, em casos mais graves, no óbito desses pacientes. Além disso, um mesmo fármaco pode ter diferentes efeitos a depender da dose e da via de administração utilizada. No caso das vias enterais, a droga pode depender ou não da metabolização hepática, o que impacta diretamente na sua biodisponibilidade. Já as vias parenterais podem ter efeitos sistêmicos ou regionais dependendo do estado fisiológico do paciente e da via de administração. Alterações nos parâmetros hemodinâmicos podem alterar a absorção da droga, o que pode diminuir a segurança dessa via (Huang et al., 2017).

As vias digestivas ou enterais são aquelas em que o fármaco necessita passar por algum segmento do trato gastrointestinal, sendo que o intestino delgado é o principal local de absorção para a via oral. No caso de ocorrer passagem pelo fígado, a droga tende a ser metabolizada em maior ou menor grau, o que impacta na concentração da droga que chega à circulação sistêmica e, consequentemente, no seu efeito (Spinosa et al., 2017). Dessa forma, essa via depende do fluxo sanguíneo, pois à medida que o fluxo sanguíneo aumenta, mais fármaco chegará aos tecidos e a absorção do fármaco também irá aumentar. No entanto, se essa taxa de irrigação sanguínea diminui, a absorção irá diminuir na mesma proporção.

Portanto, essa revisão bibliográfica tem como objetivo abordar as vias de administração e medicamentos mais utilizados na espécie felina, bem como suas diferentes doses, de forma a reforçar conceitos ministrados a discentes de graduação em Medicina Veterinária.

\section{Vias enterais}

As vias digestivas ou enterais são aquelas em que o fármaco necessita passar por algum segmento do trato gastrointestinal para fazer seu efeito, podendo ser dividida em oral, transmucosa e intrarretal (Vale \& Sousa, 2018).

\section{$>$ Com passagem pelo figado}

\section{- Via oral}

A via oral apresenta como principais vantagens permitir que o fármaco seja armazenado de forma mais estável e seja de mais fácil transporte (Panontin \& Oliveira, 2017). No entanto, algumas características podem alterar a porcentagem do fármaco que chega à circulação sistêmica, tais como velocidade de desagregação e dissolução (Panontin \& Oliveira, 2017).

No caso dos carnívoros, a absorção é determinada pela velocidade com que o medicamento sai do estômago, visto que o intestino delgado é o principal responsável por esse processo, devido a sua extensa superfície de absorção e sua rica vascularização (Spinosa et al., 2017). O período de latência é demorado, podendo variar de uma a doze horas (Massone, 2017). Em alguns casos, esse medicamento pode chegar até a bile, mecanismo conhecido como efeito de primeira passagem.

Quando um medicamento é administrado pela via oral, ele será absorvido no trato gastrointestinal, chegará ao fígado pela veia porta e poderá voltar ao intestino por meio da secreção biliar. Esse fenômeno é conhecido como circulação entero-hepática e gera o efeito de primeira passagem, o qual diminui a concentração do medicamento antes que este atinja a circulação sistêmica, devido a metabolização hepática que diminui a biodisponibilidade do fármaco. Nesses casos, é necessário que seja aplicada uma dosagem maior se comparado a outras vias (Papich, 2012; Riviere \& Papich, 2018).

$\mathrm{Na}$ representação gráfica (Gráfico 1) esse efeito pode ser observado na curva que relaciona a concentração plasmática ao longo do tempo, apresentando picos secundários na concentração plasmática após a sua absorção. Para alguns fármacos, é interessante que o animal seja alimentado antes, a fim de que ocorra a secreção de ácido biliar e micelas associadas que contribuam para a solubilização e absorção dos fármacos (Riviere \& Papich, 2018).

Nos tópicos abaixo, são apresentados antiarrítmicos, antibióticos, antiparasitários, antiplaquetários, diuréticos, imunossupressores e sedativos que podem ser utilizados por essa via, bem como as finalidades para as quais são administrados. 
Antiarrítmicos

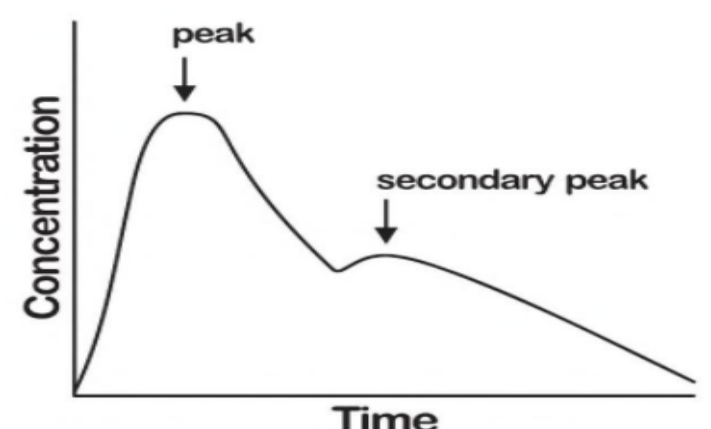

Figura 1. Representação do pico secundário observado no processo de reciclagem hepática (efeito de primeira passagem). Fonte: Riviere \& Papich (2018).

\section{Atenolol}

O atenolol (Figura 7) é um betabloqueador usado principalmente no tratamento de arritmias e hipertensão arterial, embora também possa ser útil no controle do hipertireoidismo (Bonagura \& Kirk, 1992). O uso desse medicamento sem associação a inibidores da ECA (enzima conversora de angiotensina) ou a fármacos como a amlodipina, não exerce efeitos positivos sobre o controle da pressão em gatos (Henik et al., 2008). Isso ocorre uma vez que os inibidores serão responsáveis por promover vasodilatação e evitar o acúmulo de líquidos (Ford \& Mazzaferro, 2013; Fraser et al., 1996); enquanto que a amlodipina atua bloqueando os canais de cálcio para melhor controle da hipertensão arterial (Carvalho, 2009). Pode ser usado duas vezes ao dia, via oral (Nelson \& Couto, 2015). Para o tratamento de hipertensão arterial sistêmica em gatos é utilizado atenolol a cada 12h via oral (Carregaro et al., 2004; Tebaldi et al., 2015).

Segundo Papich (2012) a dose em gatos seria de $1-2 \mathrm{mg} / \mathrm{kg}$ a cada 12 horas, por via oral. No entanto, dado o tamanho do comprimido, uma dose comumente utilizada é a de 6,25-12,5 mg/gato a cada 12-24 horas, por via oral (Papich, 2012). Nos casos de taquiarritmias é usado uma dose de 0,5 a $1 \mathrm{mg} / \mathrm{kg}$, via oral, uma vez ao dia (Spinosa et al., 2017).

\section{Broncodilatadores}

\section{Terbutalina}

A terbutalina (Figura 7) apresenta como principal efeito a broncodilatação. Para isso, este medicamento pode ser utilizado para pacientes que não respondem aos tratamentos convencionais, feitos por via inalatória (Decian, 2019). Além disso, também apresenta propriedades antiarrítmicas, podendo ser empregada no tratamento de bradiarritmias via oral, duas ou três vezes ao dia (Plumb, 2018).

\section{Antibióticos}

\section{Cefalexina}

A cefalexina (Figura 7) é um antibiótico utilizado principalmente no tratamento de infecções causadas por bactérias Gram positivas e em casos específicos Gram negativas aeróbias (Greene et al., 1993; Hartmann \& Baneth, 2006) como cistites, dermatites e pneumonias. Em gatos deve ser utilizada duas vezes ao dia, via oral, quando o tratamento é feito em casa (Papich, 2012). Em casos mais graves, como estado de choque e sepse, os antibióticos de uso oral devem ser evitados, uma vez que sua absorção é menor, devendo se dar preferência aos administrados pelas vias parenterais (Plumb, 2018).

\section{Doxiciclina}

A doxiciclina é um antibiótico de amplo espectro, utilizado principalmente por via oral, no tratamento de infecções por Chlamydophila, úlceras de córnea e conjuntivite bacteriana (Maddison et al., 2010). Considerando que este fármaco é substrato da glicoproteína $\mathrm{P}$, assim como o omeprazol (Bergman, 2003), sugere-se que essa associação, tão comum nas clínicas veterinárias, não seja feita, 
uma vez que os dois fármacos competem pelo mesmo sítio de ligação, diminuindo a absorção de ambos, deixando mais fármaco livre, o que pode levar a efeitos colaterais.

\section{Penicilina}

As Penicilinas que são administradas por via oral (igura 7) são contraindicadas no tratamento de infecções em felinos recém-nascidos, uma vez que a absorção dos seus metabólitos é desconhecida (Ozanam, 2007). Existem vários grupos que serão discutidos ao longo do artigo, mas dentre eles, a Penicilina $\mathrm{V}$ é uma das únicas que pode ser administrada via oral, pois é mais estável em locais com o pH ácido, e possui baixo espectro de ação. Já a Penicilina $G$ não atinge taxas de absorção ideais por essa via, uma vez que sofre hidrólise na presença do ácido gástrico (Maddison et al., 2010).

\section{Antiparasitários}

\section{Pamoato de pirantel}

O pamoato de pirantel é um anti-helmíntico, que pode ser administrado via oral (Figura 7) junto com o alimento. Pode ser utilizado em felinos com mais de duas semanas de vida (Pereira, 2011). Além disso, é o fármaco de eleição para o tratamento da toxocaríase em gatos e, para a eliminação das formas imaturas, devem ser realizadas duas doses, com intervalo de 15 dias entre elas (Campos et al., 2015).

\section{Praziquantel}

O praziquantel é um anti-helmíntico eficaz sobre cestódeos das famílias Taeniidae e Dipylidiidae de gatos, incluindo as fases adulta e de larva. Para o tratamento de cestódeos, pode ser administrado por via oral (Spinosa et al., 2017), podendo utilizar também em associação comercial dos princípios ativos Pamoato de pirantel e praziquantel, um vermífugo oral de dose única de amplo espectro para gatos (Lignon et al., 2019).

O praziquantel também é o medicamento de escolha no tratamento contra Platynosomum illiensis, o trematódeo que parasita ductos biliares de gatos (Spinosa et. al., 2017). No entanto, este fármaco não é recomendado em gatos com menos de seis semanas de idade, período de vida mais comum de infestação por esse parasito (Plumb, 2018).

\section{Fembendazol}

O fembendazol é um anti-helmíntico utilizado para tratamento de parasitas pulmonares, como o Aelurostrongylus abstrusus; fascíolas e vermes helmínticos (tênias, strongyloides, lombrigas). A duração do tratamento pode ser estendida por 5 dias para as infestações parasitárias graves (Papich, 2012). Para tratamento de felinos com Aelurostrongylus abstrusus os protocolos com o fármaco fembendazol são bastante variados com relação ao tempo de utilização, dentre eles têm -se a utilização de $50 \mathrm{mg} / \mathrm{kg}$, a cada 24 horas, vira oral, durante 3, 5 ou 14 dias (Campos et al., 1974)

\section{Antiplaquetários}

\section{Clopidogrel}

O clopidogrel (Figura 7) é um antiplaquetário utilizado principalmente para a prevenção do tromboembolismo aórtico em pacientes felinos com doenças cardiovasculares (Site, 2006; Smith et al., 2003). Apesar disso, existe a necessidade de serem realizados mais estudos que comprovem a eficácia do efeito terapêutico nessa espécie (Bonagura \& Kirk, 1992). De acordo com esses autores, para evitar ocorrência de êmese, é recomendado que o clopidogrel seja administrado junto com o alimento.

\section{Diuréticos}

\section{Espironolactona}

A espironolactona (Figura 7) é um diurético, que apresenta atividade poupadora de potássio (Plumb, 2018), usado principalmente no controle da pressão arterial e para o controle do hiperaldosteronismo, quando administrado em associação com outros fármacos (Razal et al., 2020). Ela é indicada para pacientes com insuficiência cardíaca congestiva refratária associada ao tratamento com furosemida e inibidores da ECA (Bonagura \& Kirk, 1992). 


\section{Furosemida}

A furosemida (Figura 7) é um diurético muito eficiente, que pode ser usado no tratamento de retenção de líquidos livres em doenças cardiovasculares que levam a formação de edemas sistêmicos, e no estímulo da micção no caso das doenças renais, independentemente do seu estágio (Fiorini et al., 2017).

\section{Imunossupressores}

\section{Ciclosporina}

A ciclosporina (Figura 7) é um imunossupressor usado principalmente para o tratamento de doenças dermatológicas como o complexo granuloma eosinofílico e dermatites atópicas, embora também possa ser empregada na terapêutica da doença intestinal inflamatória, inflamações orais, afecções respiratórias e oftalmológicas (Papich, 2012). Seu uso deve ser evitado em animais que possuem o Vírus da Imunodeficiência Felina (FIV), ou em outras doenças virais, uma vez que pode prejudicar o sistema imune desses pacientes, pois leva a imunodepressão (Ferreira et al., 2011; Poffo, 2012). Doses maiores, devem ser feitas em dias alternados, exceto no caso de pacientes transplantados, no qual pode ser feita a cada 12 horas (Papich, 2012). É empregada principalmente em processos inflamatórios intensos a fim de diminuir a resposta imune exacerbada, como no caso da gengivoestomatite (complexo gengivite estomatite faringite) felina, mas, nesses casos, não pode ser usada por períodos prolongados (Cubas et al., 2014).

\section{Dexametasona}

O succinato sódico de dexametasona por via oral (Figura 7) é recomendado principalmente para o tratamento da bronquite crônica no intervalo de até três vezes ao dia. Assim que o paciente fica estável, a dose é diminuída e passa a ser administrada em dias alternados, até a remissão dos sintomas (Plumb, 2018). É recomendável utilizar a menor dose no menor intervalo de tempo possível, uma vez que, sendo um mineral corticoide muito potente, esse fármaco pode causar a Síndrome de Cushing, doença endócrina ocasionada pelo acúmulo de cortisol no organismo, apesar dos gatos sofrerem menos com os efeitos adversos (Ferreira et al., 2011; Plumb, 2018; Poffo, 2012).

\section{Sedativos}

\section{Diazepam}

O diazepam pode ser utilizado pela via oral (Figura 7) quando se tem por objetivo proporcionar relaxamento muscular, estimular o apetite e promover a sedação, no caso de ser utilizado no protocolo pré-anestésico (em doses menores), sendo recomendado a administração nesses casos a cada 8 horas. (Maddison et al., 2010; Sandem et al., 2006).

\section{$>$ Vias que não possuem passagem pelo fígado}

\section{- Via transmucosa oral}

A via transmucosa oral tem por objetivo evitar o efeito de primeira passagem, por ser uma via de fácil acesso, menos invasiva e dolorosa que permita a absorção de forma direta e rápida devido à grande vascularização presente, aumentando consequentemente a biodisponibilidade dos medicamentos administrados (Sobeck et al., 2003), além de reduzir o estresse do animal e facilitar a contenção física (Bortoli \& Ribeiro, 2019). No entanto, apesar de sua facilidade de administração, outros fatores devem ser levados em consideração em casos nos quais são utilizados analgésicos e sedativos, especialmente com relação ao nível de sedação dentre os quais podem-se destacar: a vasoconstrição periférica, a qual diminui a concentração do fármaco no local em que foi administrado, a sialorreia, responsável pela sua diluição que diminui a concentração plasmática do medicamento, a constante de acidez e o grau de solubilidade do fármaco ( $\underline{\text { Santos et al., 2010) }}$.

\section{Analgésicos}

\section{Metadona}

Como exemplo dessa via, tem-se a metadona, um opioide forte, que quando administrado pela via transmucosa oral apresenta biodisponibilidade moderada e seus efeitos são similares ao da via 
intravenosa. No entanto, uma pequena dose do fármaco pode ser perdida na saliva e por essa razão esse medicamento não pode ser usado de forma única, mas sim como adjuvante durante a anestesia ou como medicação pré-anestésica (Campagnol, 2011). Além disso, as concentrações plasmáticas observadas na via transmucosa oral são menores quando comparadas a via intravenosa (Figura 2), acarretando na sua absorção mais lenta (Ferreira et al., 2011).

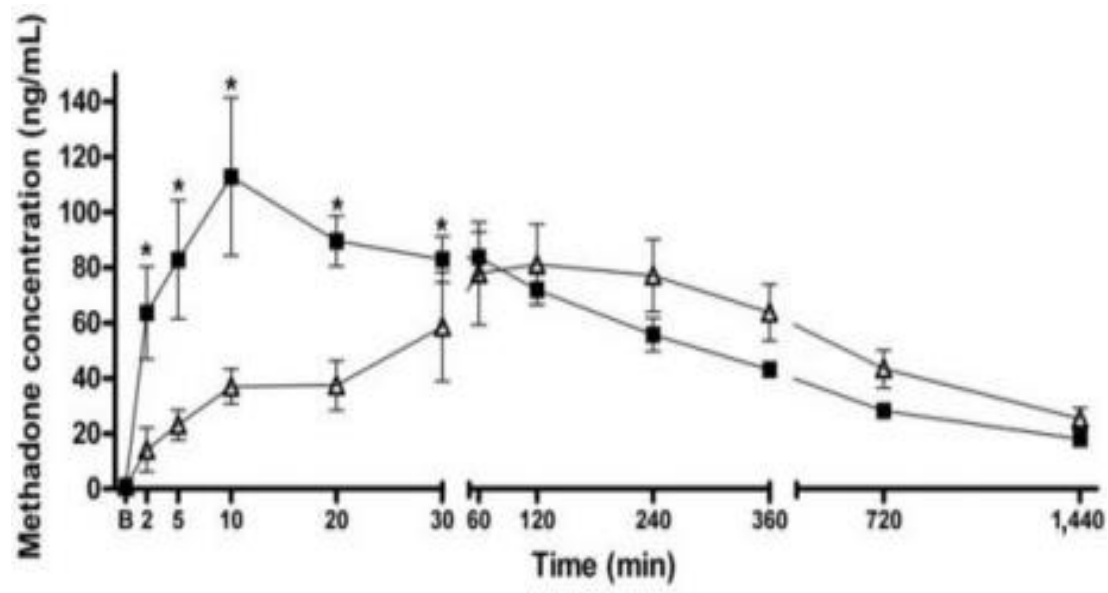

Figura 2. Concentração plasmática da Metadona ao longo do tempo após administração intravenosa (representada pelos quadrados em negrito) e transmucosa oral (representada por triângulos). Nesse estudo foram utilizados 8 gatos saudáveis, sendo que cada um recebeu o fármaco com um intervalo maior ou igual a 10 dias entre os 2 tratamentos. O pico da concentração plasmática foi observado 10 minutos após a administração intravenosa, enquanto o da via transmucosa oral foi detectado somente após 120 minutos. Fonte: Ferreira et al. (2011).

\section{Sedativos}

\section{Dexmedetomidina}

A Dexmedetomidina (Figura 7) é usada para fins sedativos, analgésicos e para relaxamento muscular, sendo seguro para gatos (Fantoni \& Cortopassi, 2009; Plumb, 2018). No entanto, quando usada pela via transmucosa oral, apresenta absorção mais lenta, menor concentração e, consequentemente, menor grau de sedação se comparada a via intramuscular, o que acarreta na absorção mais lenta (Figura 3). Por essa razão, é mais indicado que seja feita como medicação pré-anestésica.

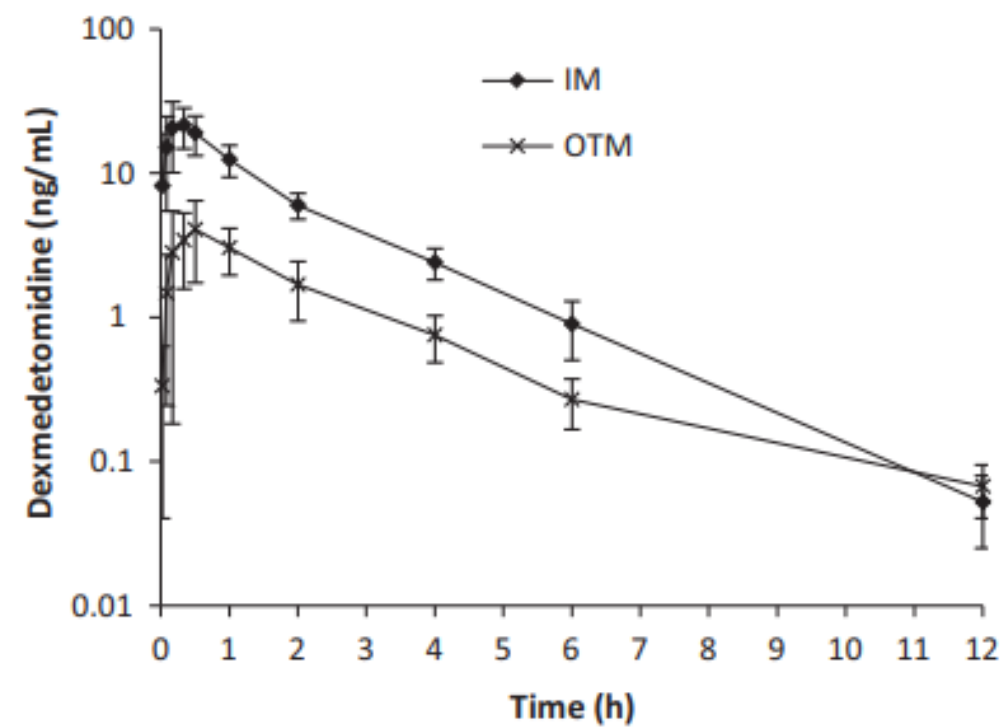

Figura 3. Concentração plasmática de Dexmedetomidina e Buprenorfina ao longo do tempo após administração transmucosa oral (OTM) e intramuscular (IM) em 6 gatos saudáveis. Fonte: Porters et al. (2015). 


\section{- Via retal}

A via retal tem por objetivo administrar formas farmacêuticas na mucosa retal, de maneira que sejam absorvidos pelo plexo hemorroidário e produzam efeitos sistêmicos (Booth \& McDonaldo, 1992). Nesses casos, o medicamento pode sofrer moderadamente o efeito de primeira passagem. Todavia, o que dificulta a sua utilização é o fato de apresentar absorção irregular, além de poder lesionar a superfície da mucosa retal (Spinosa et al., 2017). Apesar disso, é a via de escolha para pacientes inconscientes em estados convulsivos para administração de fármacos que são possíveis de se hidrolisarem em pH ácido (Reis, 2015).

\section{Anticonvulsivantes}

\section{Diazepam}

Essa via é muito usada para a administração de supositórios de Diazepam (Figura 7) nos casos de convulsões de emergência e status epilepticus, situações em que se tem difícil acesso a outras vias (Spinosa et al., 2017). Nesses casos o fármaco pode exercer efeito local ou sistêmico.

\section{Vias parenterais}

As vias parenterais tem por objetivo administrar drogas de forma que atinjam diretamente a circulação sistêmica para que o efeito ocorra mais rapidamente (Booth \& McDonaldo, 1992). Podem ser divididas entre as que geram perfuração epitelial e que, consequentemente, necessitam de uma maior esterilização, e as que não necessitam perfurá-lo. As vias perfurantes exigem maior controle microbiológico e podem ser agrupadas nos seguintes grupos:

$>$ Vias que possuem efeito sistêmico: intravenosa, intramuscular, subcutânea, intracardíaca, intraóssea e intraperitoneal.

> Vias que produzem efeito local ou regional: subcutânea, ocular, intradérmica, epidural, perfusão regional e intralesional.

\section{- Via intravenosa}

Por essa via são aplicadas soluções aquosas que possuem concentrações iniciais superiores logo após sua administração e um rápido período de latência. As formulações irritantes e não isotônicas podem ser injetadas via intravenosa desde que esse processo seja feito com cautela e vagarosamente (Boothe, 2011). Nos gatos, está diretamente relacionada a cuidados críticos, pois permite uma maior eficácia do medicamento no menor tempo possível, mas, deve-se ter cautela com a ocorrência de embolias e infecções iatrogênicas. Para isso, são feitos acessos principalmente através das veias radial, femoral e a tarsal recorrente (Spinosa et al., 2017).

Quando essa via é utilizada, apresenta um efeito mais rápido que as das vias intramuscular e subcutânea, a qual possui suas concentrações mais prolongadas, sendo responsável por efeitos mais duradouros (Booth \& McDonaldo, 1992) (Figura 4).

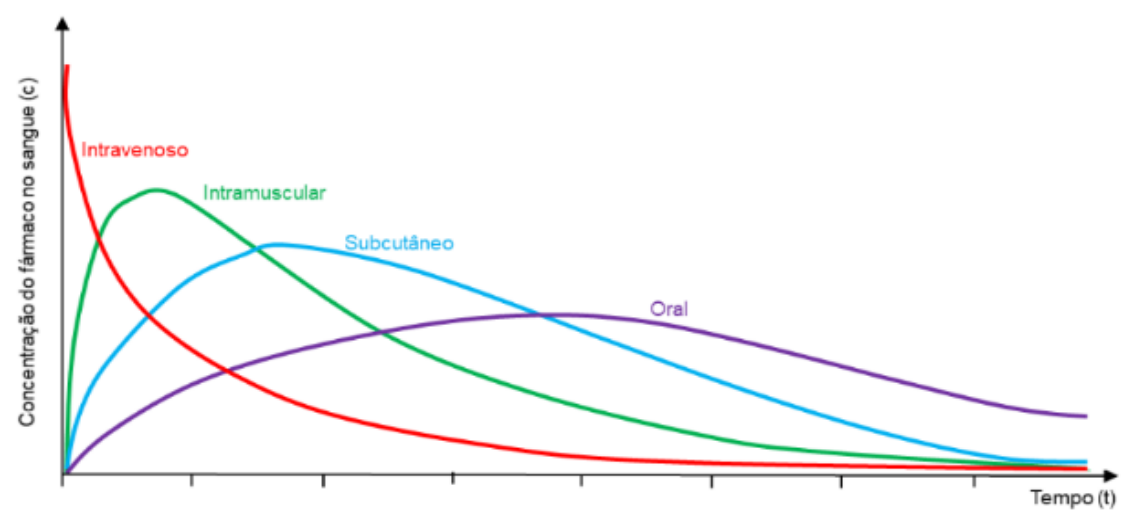

Tabela 4. Efeito das diferentes vias de administração ao longo do tempo. Fonte: Adaptado de Juraski et al. (2017). 
São listados abaixo os principais fármacos administrados por via intravenosa na espécie felina, bem como suas respectivas funções.

\section{Anestésicos}

\section{Cloridrato de Cetamina}

A cetamina, quando administrada por via intravenosa (Figura 7), tem por objetivo principal a analgesia quando atinge a circulação sistêmica, mas além disso pode ser usada na indução e manutenção anestésica (Plumb, 2018). Deve se ter cuidado com a dose administrada, uma vez que pode acarretar em depressão respiratória (Spinosa et al., 2017).

\section{Propofol}

O propofol (Figura 7), de forma isolada é recomendado para cirurgias mais rápidas, por ser um anestésico de curta duração. Em gatos, é administrado apenas pela via intravenosa, e não deve ser utilizado em animais com a pressão arterial baixa, uma vez que pode levar a falta de ar, hipóxia e, consequentemente, cianose (Papich, 2012).

\section{Xilazina}

A xilazina quando usada pela via intravenosa (Figura 7), tem a finalidade de sedar os animais, eliminar a dor e provocar relaxamento muscular (Emilio et al., 2004). Em gatos, apresenta uma boa margem de segurança e pode ser administrada também nas formas subcutânea e intramuscular (Seli et al., 2005).

\section{Corticosteroides}

\section{Dexametasona}

O Succinato sódico de Dexametasona por via intravenosa (Figura 7) é indicado para casos onde há choque endotóxico, sepse, traumatismos que envolvam o sistema nervoso central ou periférico, e na insuficiência de adrenal (Spinosa et al., 2017). Além disso, pode ser feita para a realização de provas de supressão, a fim de diagnosticar o hiperadrenocorticismo felino (Marco et al., 2012; Moreira, 2009; Rosa et al., 2011) e para problemas respiratórios, como a asma felina.

\section{Diuréticos}

\section{Furosemida}

Quando feita em bolus intravenoso, ou seja, em infusão rápida, a furosemida (Figura 7) tem por objetivo diminuir a dispneia causada por edema pulmonar cardiogênico a nível hospitalar, em associação com a oxigenioterapia e outros medicamentos que auxiliam na terapia de suporte (Maddison et al., 2010).

\section{Antiarrítmicos}

\section{Lidocaína}

No caso da lidocaína, a via intravenosa (Figura 7) é usada principalmente para efeitos antiarrítmicos, de forma lenta ou por meio da infusão contínua (Papich, 2012). Para isso, é necessário um monitoramento rigoroso durante a sua ministração, pois os gatos são muito sensíveis aos efeitos neurológicos desse fármaco (Plumb, 2018).

\section{Antibióticos}

\section{Penicilina}

A penicilina cristalina (Figura 7) é recomendada para infecções severas como pielonefrites e não pode ser usada pela via intramuscular pois é muito dolorosa, devendo priorizar a via intravenosa ( $\underline{\text { Santos }}$ et al., 2006). A administração de antibióticos por essa via é mais indicada para casos graves e é feita com o objetivo de curar infecções secundárias (Arias et al., 2008).

\section{Broncodilatadores}

\section{Terbutalina}

A terbutalina (Figura 7) é utilizada no âmbito hospitalar para finalidades broncodilatadoras (Decian, $\underline{2019}$ ) e seu período de latência pode levar até 30 minutos (Biesalski, 2001). 


\section{- Via tópica}

A via tópica usualmente é usada para fins localizados, entretanto, algumas substâncias podem ser absorvidas mesmo que a pele esteja íntegra (Spinosa et al., 2017). Caso a pele esteja lesionada, podem haver efeitos adversos locais e sistêmicos e, por essa razão, deve-se ter cautela ao optar por essa via (Spinosa et al., 2017).

Como exemplos, têm-se as formulações pour on, na qual uma solução é aplicada sobre o epitélio da linha dorsal, e a spot on, onde o fármaco é colocado em uma região específica, sendo mais comum para o controle de ectoparasitas, são exemplos de fármacos representadas pelo fipronil e o imidacloprid (Castro-Janer et al., 2010). Geralmente, os fármacos usados são lipossolúveis para que se solubilizem na gordura e permitam a chegada da droga por toda a extensão do corpo do animal (Spinosa et al., 2017).

O processo de absorção pode ser ampliado com o uso de curativos obstrutivos, que hidratam as camadas do estrato córneo, ou substâncias que alterem as estruturas dessa camada, como o dimetilsulfóxido, a ureia a 10\% e ácido oleico de 15 a 20\% (Boothe, 2011; Cubas et al., 2014). Os principais fármacos utilizados por essa via são anestésicos, analgésicos, antiarritímicos e antiparasitários são descritos a seguir.

\section{Anestésicos}

\section{Cloridrato de lidocaína}

A lidocaína (Figura 7) é usada principalmente para fins relacionados a anestesia local, mas depois que atinge a circulação sistêmica adquire propriedades antiarrítmicas e analgésicas, sendo a espécie felina mais sensível aos efeitos colaterais. Por essa razão, nessa espécie é necessário ser cauteloso com as doses. Esse anestésico quando usado na forma de adesivo apresenta menos efeitos adversos nos felinos, visto que a absorção é relativamente menor (Papich, 2012), mas essa forma ainda é pouco utilizada na veterinária (Valadão et al., 2010).

\section{Antiparasitários}

\section{Fipronil}

O fipronil (Figura 7) é um antiparasitário seguro, comumente utilizado para a eliminação de pulgas e carrapatos em gatos pela via spot on. No entanto, ao ser administrado incorretamente, para espécies diferentes e sem respeitar a dose adequada indicada na fórmula, pode acarretar em efeitos colaterais de ordem cutânea, neurológica, gastrointestinal ou ocular (Capuano \& Rocha, 2006; Farias et al., 1995; Tesserolli et al., 2005). Além disso, alguns estudos têm demonstrado que seu uso pode causar alterações comportamentais e cognitivas nesses animais, mas ainda não é um fato comprovado.

\section{Imidacloprid}

O imidacloprid (Figura 7) tem sua atuação a nível sistêmico, assim como o fipronil (Capuano \& Rocha, 2006; Farias et al., 1995; Tesserolli et al., 2005), mas como tem uma absorção menor nas camadas epiteliais, apresenta menos efeitos adversos se comparado a outros antiparasitários (Short \& Gram, 2016). Ao ser administrado via spot on, devem ser obedecidas as especificações descritas pela empresa, respeitando a espécie para a qual a formulação é indicada. bem como o peso para cada animal, de forma a evitar possíveis intoxicações (Capuano \& Rocha, 2006; Farias et al., 1995; Tesserolli et al., 2005).

\section{- Via intranasal}

A via intranasal é usada para procedimentos simples e rápidos, como exames radiográficos e coleta de materiais biológico, principalmente para anestésicos e opioides (Spinosa et al., 2017). Nesses casos, os fármacos são absorvidos a partir da mucosa nasal devido a extensa área de vascularização e seguem em direção a circulação sistêmica (Ramalhais \& Ribeiro, 2020). Como vantagens, essa via apresenta rápida absorção e recuperação pós anestésica, além de uma elevada biodisponibilidade farmacológica (Surendar et al., 2014). 


\section{Anestésicos}

\section{Cetamina}

A cetamina em combinação com o midazolam quando usada para fins anestésicos, têm mostrado efeitos sedativos semelhantes aos da via intramuscular, quando utilizados pela via intranasal, de acordo com Marjani et al. (2015). Nesse estudo, foi demonstrado que o tempo de início, duração e recuperação anestésica foram muito próximos, fator que justifica seu uso principalmente em animais mais estressados (Marjani et al., 2015).

\section{Midazolam}

O midazolam é um relaxante muscular de ação central que pode ser utilizado como medicação préanestésica (Bauer et al., 2004) e no controle da epilepsia. Quando administrado pela via intranasal, a sua duração é similar à administração via oral, apesar do seu início de ação ser mais rápido (Bauer et al., 2004).

Opioides

\section{Nalbufina}

A nalbufina é um analgésico utilizado para dores leves a moderadas que pode ser administrado pela via intranasal após os procedimentos cirúrgicos. Além disso, também apresenta um certo índice sedativo e é considerado seguro por apresentar pouca alteração sobre o sistema cardiorrespiratório (Bauer et al., 2004).

\section{- Via epidural}

A via epidural é usada principalmente para cirurgias abdominais. É uma técnica fácil, que apresenta poucos riscos e eficaz, já que altera minimamente os parâmetros cardíacos e respiratórios, facilita a analgesia no pós-operatório, além de diminuir a inquietação durante o procedimento cirúrgico. (McKelvey \& Hollingshead, 1994). Além disso, é comum de ser empregada em anestesias para aplicação de analgésicos e anestésicos na região a partir da qual nervos aferentes são conduzidos até a medula espinhal. Para sua realização, pode ser usado qualquer espaço intervertebral que esteja na porção lombar do animal, mas o mais comumente utilizado é o lombossacro entre L7 e S1 (Aleixo \& Tudury, 2007; Bressan, 2017; Valadão et al., 2010).

\section{Anestésicos}

\section{Cloridrato de bupivacaína}

O cloridrato de bupivacaína (igira 7) é um anestésico local que apesar do seu início de ação lenta, possui efeito mais duradouro que outros anestésicos locais. É usado principalmente para infiltração local ou infusão no espaço peridural (Massone, 2017; Papich, 2012). Como vantagens, apresenta pouca variação dos parâmetros cardiovasculares, proporcionando assim, uma anestesia mais segura (Magalhães et al., 2004).

\section{Analgésicos}

\section{Morfina}

No caso dos opioides, a solubilidade do fármaco é o fator que mais influência na sua distribuição. Por ser pouco lipossolúvel, a Morfina, por exemplo, permanece por mais tempo na medula óssea, o que potencializa a duração dos seus efeitos (Aleixo \& Tudury, 2007; Bressan, 2017; Valadão et al., 2002).

\section{- Via ocular}

O tratamento das afecções oculares é dificultado pela presença de barreiras oculares representadas pela córnea, estroma, retina, esclera, endotélio e barreira hemato-ocular que impede a chegada dos fármacos a esse local. Com o objetivo de contornar esses obstáculos, podem ser feitas formulações que facilitem a liberação do fármaco de forma que o gradiente de concentração consiga colocar o fármaco no interior do olho (Spinosa et al., 2017). 


\section{Antibióticos}

\section{Cloranfenicol}

O cloranfenicol é um fármaco altamente lipossolúvel, sendo usado principalmente nos tratamentos onde há comprometimento de córnea. Apesar de apresentar um amplo espectro contra bactérias Gram negativas e positivas, não é eficaz para infecções que envolvam a bactéria Pseudomonas aeruginosa, sendo que nesses casos deve-se optar por outros fármacos ou por uma associação com polimixina $\mathrm{B}$ (Maddison et al., 2010).

\section{Gentamicina}

A gentamicina é um antibiótico de amplo espectro que pode ser utilizada para o tratamento de afecções de córnea causados por Pseudomonas aeruginosa que apresenta poucos problemas relacionados à resistência bacteriana (Lopes et al., 2019).

\section{Tobramicina}

A tobramicina é um antibiótico pertencente à classe dos aminoglicosídeos encontrada tanto na forma de pomada quanto na forma de colírios. É muito parecida com a Gentamicina e pode ser usada em afecções oculares mais graves (Maddison et al., 2010).

\section{Anestésicos}

\section{Atropina}

A Atropina é um colírio anestésico que pode ser usado tanto para o diagnóstico, como para o tratamento da úlcera de córnea em gatos. Apesar de ser usada para efeito tópico, a Atropina pode ter efeito sistêmico, agindo de forma a reduzir a dor decorrente dos espasmos do corpo ciliar (Silva et al., $\underline{2015}$ ). Esse fármaco também pode ser utilizado no pós-operatório do flap de terceira pálpebra em associação a colírios antibacterianos (Viega, 2018).

\section{- Via intralesional}

É usada quando se tem a necessidade de administrar um fármaco que é tóxico para a circulação, quando o sítio de ação é de difícil acesso, ou quando não há possibilidade da realização de técnicas cirúrgicas.

\section{Quimioterápicos}

\section{Carboplatina}

A carboplatina é um medicamento utilizado para a realização de quimioterapia intralesional e, que vem demonstrado respostas bastante satisfatórias na terapêutica de carcinoma de células escamosas em felinos. Estudos demonstram que essa prática apresenta poucos efeitos adversos, além de ser mais acessível e não requerer equipamentos de difícil acesso, facilitando o processo curativo (Ximenes et al., 2018).

\section{Anfotericina B}

A anfotericina B por essa via é usada principalmente para o tratamento da esporotricose, em pacientes que não respondem ao uso de itraconazol sistêmico (Reis et al., 2016). Para isso, a Anfotericina pode ser diluída com um anestésico local e ser aplicada semanalmente ou quinzenalmente (Gremião et al., $\underline{2015}$.

\section{- $\quad$ Via intramuscular}

Para a via intramuscular podem ser usadas soluções aquosas, oleosas ou outras formulações, como suspensões. A absorção pode ocorrer na circulação sanguínea ou linfática e costuma ser rápida, a não ser que a preparação seja para medicamentos de longa ação (Boothe, 2011). Deve-se ressaltar que nessa via não podem ser aplicados fármacos em concentrações elevadas ou com o $\mathrm{pH}$ diferente do $\mathrm{pH}$ do tecido de aplicação, uma vez que essa ação pode resultar em processos necróticos, como no caso de 
barbitúricos ou éter gliceril guaiacólico a 10\% (Massone, 2017). Além disso, costuma optar-se por essa via quando a intravenosa é de difícil acesso, principalmente em situações de emergência.

\section{Anestésicos e sedativos}

\section{Dexmedetomidina}

Quando usada pela via intramuscular a dexmedetomidina (Figura 7) pode ser feita como préanestésico, sedativo e anestésico para procedimentos rápidos, sendo que seu efeito tem duração de aproximadamente uma hora (Plumb, 2018).

\section{Xilazina}

A xilazina (Figura 7) é usada com a finalidade de sedar os animais, eliminar a dor e provocar relaxamento muscular (Spinosa et al., 2017). Em gatos, quando usada pela via intramuscular tem por finalidade principal a indução do vômito, sobretudo em casos de intoxicação (

\section{Cloridrato de cetamina}

A cetamina (Figura 7) é um anestésico seguro de ação rápida, além de exercer efeitos analgésicos significativos. Em gatos, pode ser feita via intramuscular para efeitos de sedação, contenção e medicação pré-anestésica em procedimentos mais simples e curtos (Plumb, 2018).

\section{Medetomidina}

A medetomidina (Figura 7) provoca sedação e analgesia de acordo com a dose administrada (Vainio, 1989). É similar a xilazina, mas devido a sua maior seletividade aos receptores alfa2-adrenérgicos exerce maior efeito. Caso essas duas drogas exerçam efeitos colaterais, a droga de eleição para reversão é o atipamezole (Savola, 1989). Caso seja administrada via intramuscular pode induzir a êmese (Virtanen \& MacDonald, 1985).

\section{Antibióticos}

\section{Penicilina}

A penicilina (Figura 7) é um antibiótico que pode ser subdividido em vários grupos, e por esse motivo tem diferentes vias de administração. A penicilina benzatínica, por exemplo, só pode ser usada pela via intramuscular, sendo indicada principalmente para o tratamento de afecções respiratórias (Santos et al., 2006) causadas por bactérias Gram positivas.

\section{Corticoides}

\section{Succinato de metilprednisolona}

A metilprednisolona (Figura 7) é um potente anti-inflamatório que pode ser encontrado em duas formas: Succinato de metilprednisolona, caracterizado por ser um sal hidrossolúvel de absorção rápida e Acetato de metilprednisolona, sal que por apresentar maior lipossolubilidade, é absorvido mais lentamente. O primeiro, apresenta meia vida menor, de aproximadamente dois dias, enquanto o segundo é totalmente eliminado com três semanas após a sua absorção, sendo escolhido principalmente para gatos indóceis que precisam do uso prolongado de corticoides (Little, 2016).

O succinato sódico de metilprednisolona é utilizado via intramuscular para terapias antiinflamatórias e imunossupressoras. Por essa razão é empregado principalmente nos casos agudos, sobretudo de crises asmáticas (Spinosa et al., 2017).

\section{Broncodilatadores}

\section{Terbutalina}

A terbutalina é um potente broncodilatador que pode ser utilizado via intramuscular ou intravenosa em situações emergenciais (Decian, 2019; Little, 2016; Padrid, 2006; Rozanski \& Rush, 2009).

\section{- Via subcutânea}

A via subcutânea é usada para efeitos terapêuticos lentos e constantes. Nesses casos, a absorção ocorre por difusão simples e para isso o pH e a osmolaridade dos fármacos utilizados devem ter valores 
próximos ao dos tecidos para aplicação, a fim de impedir processos necróticos e dolorosos (Spinosa et al., 2017). Por essa razão, devem ser evitadas soluções irritantes e veículos oleosos. A taxa de absorção nesses casos não é calculável, pois depende do fluxo sanguíneo e outros fatores extrínsecos como a presença de vasoconstritores e vasodilatadores. No entanto, é válido afirmar que esse parâmetro farmacológico é mais lento se comparado a via intramuscular (Boothe, 2011).

Em animais normovolêmicos, as dosagens da via subcutânea são muito próximas às da via intramuscular. No entanto, em animais debilitados e nos que praticam exercício físico regularmente, a circulação pode estar alterada, modificando as taxas de absorção (Maddison et al., 2010). A administração de medicamentos injetáveis em felinos pode acarretar na formação do sarcoma de aplicação, o qual pode ser definido pela formação de neoplasias malignas decorrentes da aplicação de soluções farmacológicas e vacinas por via subcutânea ou intramuscular (Domingos et al., 2008; Ferreira \& Zimmermann, 2017; Peixoto \& Bezerra Junior, 2010). Por essa razão, prioriza-se a ministração de vacinas pela via subcutânea em contraposição a intramuscular, devido à maior facilidade de detecção dos nódulos nessa região mais superficial (Saba, 2017). Além disso, cada vacina possui um local de aplicação padronizado, visando identificar qual foi responsável pela neoformação (Saba, 2017). Assim, alguns autores recomendam que a vacina contra a raiva seja aplicada na face lateral do membro pélvico direito, a tríplice ou quádrupla felina na face lateral do membro torácico direito e a vacina contra o FeLV na face lateral do membro pélvico esquerdo (Figura 5) (Domingos et al., 2008; Ferreira \& Zimmermann, 2017; Peixoto \& Bezerra Junior, 2010).

\section{Broncodilatadores}

\section{Terbutalina}

A terbutalina via subcutânea é usada principalmente no tratamento de gatos com asma, para impedir a broncoconstrição. Essa forma de administração pode ser ensinada aos tutores logo no início das crises, de forma a evitar possíveis internações desnecessárias (Decian, 2019).

\section{Corticoides}

\section{Acetato de metilprednisolona}

$\mathrm{O}$ acetato de metilprednisolona (Figura 7) é usado para tratamentos anti-inflamatórios mais prolongados por ser mais lipossolúvel. É usado pela via subcutânea quando os efeitos precisam ser mais longos, podendo perdurar por até 6 meses (Plumb, 2018). Para animais mais agressivos que necessitam de tratamento com corticoterapia prolongada, o emprego da via subcutânea para esse fármaco é o mais recomendado (Spinosa et al., 2017).

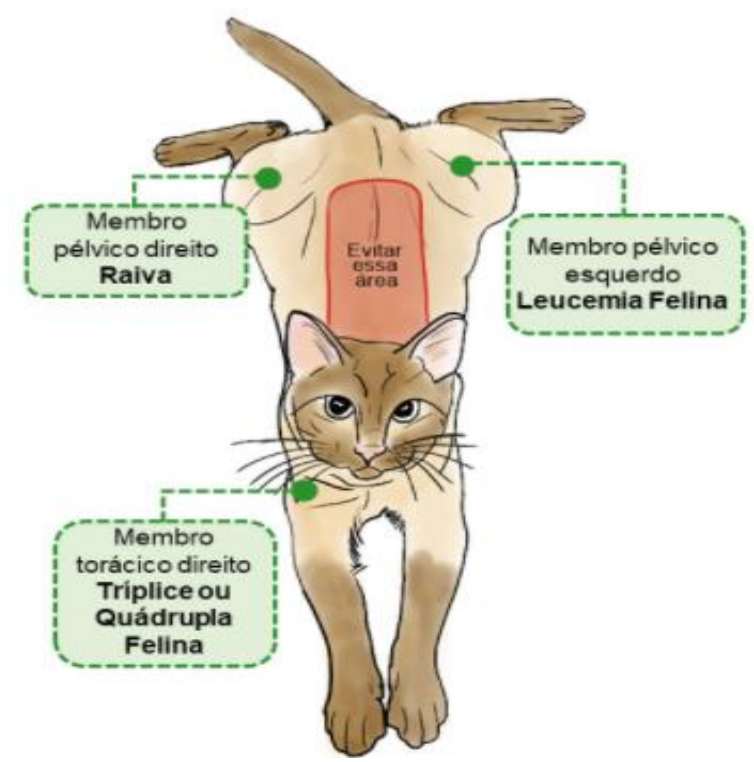

Figura 5. Locais de aplicação recomendados para a aplicação de vacinas subcutâneas. 


\section{Diuréticos}

\section{Furosemida}

A furosemida subcutânea (Figura 7) é usada principalmente no tratamento da insuficiência cardíaca crônica, quando a via oral é difícil de ser feita. A dose deve ser a mínima possível, desde que diminua os sinais clínicos e deve ser monitorada constantemente caso haja efeitos colaterais (Maddison et al., 2010).

\section{- Via intracardíaca}

É mais usada em casos de emergência quando há dificuldade no acesso venoso, como em paradas cardíacas, com o objetivo de estimular a contratilidade dos músculos cardíacos, a partir da injeção de adrenalina (Ettinger et al., 2002). Entretanto, se existir a possibilidade de escolha entre esta e a via intravenosa, deve-se optar pela via intravenosa, pois a intracardíaca tem maiores chances de lesionar os vasos. Para sua execução a agulha é colocada perpendicularmente ao tórax e posteriormente ao cotovelo, sendo utilizada também em procedimentos de eutanásia cujos medicamentos são listados a seguir.

\section{Agentes de eutanásia}

\section{Cloreto de potássio}

O cloreto de potássio pode ser utilizado pela via intracardíaca para fins de eutanásia na dose de 500 $\mathrm{mg} / \mathrm{kg}$ depois de uma anestesia profunda, usando-se cetamina e/ou xilazina (Aragão, 2012; Fighera et al., 2008; Santos \& Montanha, 2011).

\section{Pentobarbital}

O pentobarbital também pode ser utilizado em procedimentos de eutanásia pela via intracardíaca, endovenosa ou intraperitoneal. Para isso, na maioria das vezes são formulados produtos que contém Pentobarbital Sódico em sua composição em associação com anestésicos locais como lidocaína ou fenitoína (Figueiredo \& Araújo, 2001; Pulz et al., 2011; Santos \& Montanha, 2011).

\section{- Via intraóssea}

É usada em cuidados críticos com neonatos, na fluidoterapia com bombas de infusão ou equipos destinados ao tamanho do animal e transfusões sanguíneas (Ferreira \& Zimmermann, 2017). A via intra óssea oferece resultados semelhantes ao da via intravenosa, sobretudo em filhotes e pacientes com problemas circulatórios ou muito pequenos (Pereira et al., 2006). Para isso é colocado um cateter intraósseo de forma que o fármaco seja direcionado diretamente para a corrente sanguínea dos pacientes filhotes, sendo que os pontos mais utilizados para isso são a fossa intratrocantérica e a crista da tíbia (Fantoni \& Cortopassi, 2009; Polydoro et al., 2006), os quais são representados na figura 6.

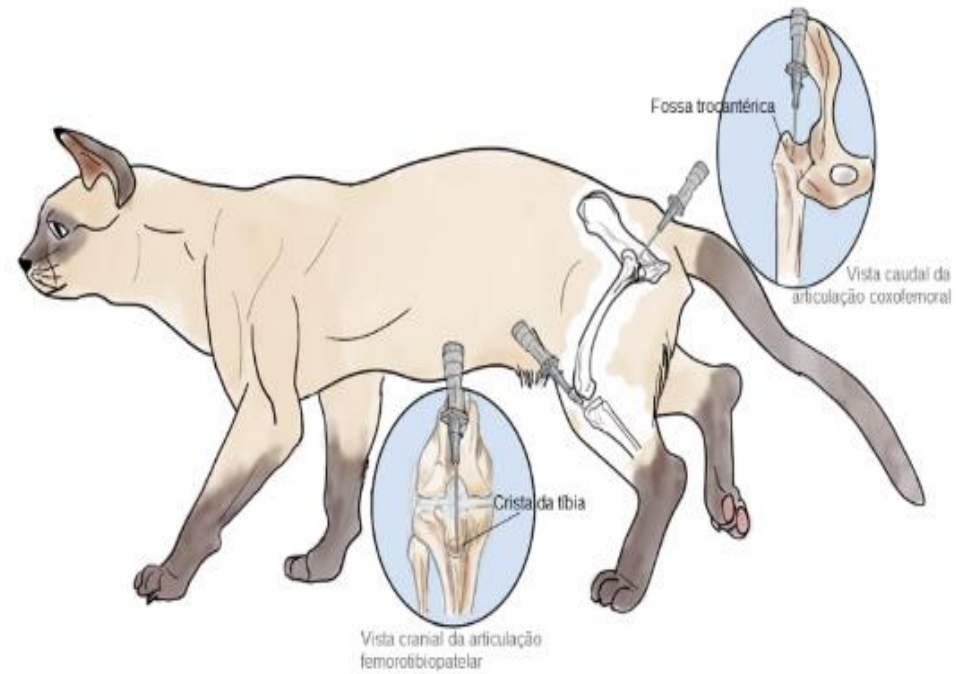

Figura 6. Principais pontos de aplicação da via intraóssea. A fossa intratrocantérica está representada na parte superior da figura, enquanto a crista da tíbia é ilustrada na parte inferior. Fonte: Adaptado de McMichael, (2011). 


\section{Soluções fluidoterápicas}

\section{Dextrose}

Normalmente, na fluidoterapia intraóssea de pequenos animais deve se dar preferência às soluções ricas em dextrose a 50\%, pois os filhotes tendem a ter hipoglicemia mais facilmente (Pereira et al., 2006).

\section{- Via inalatória (ou pulmonar)}

Substâncias gasosas e voláteis são facilmente absorvidas pelo epitélio respiratório superior e inferior. Essa característica está diretamente relacionada à intensidade dos movimentos inspiratório e expiratório, e inversamente associada à frequência respiratória (Boothe, 2011). O trato respiratório superior é frequentemente utilizado para a administração de fármacos via aerossóis, os quais apresentam uma extensa janela terapêutica e um grande padrão de segurança, além de evitar a grande circulação e a barreira que envolve o Sistema Nervoso Central (Boothe, 2011).

\section{Anestésicos}

\section{Isofluorano}

O isofluorano é um anestésico inalatório muito utilizado nos procedimentos cirúrgicos de felinos, devido a indução, recuperação e variação da profundidade anestésica serem rápidas (Ferreira et al., 2006). No entanto, pode causar hipotensão, depressão respiratória e hipercapnia, caso sejam usadas doses acima do recomendado (Ferreira et al., 2006). Esse fármaco apresenta características mais vantajosas que o halotano, devido ao seu coeficiente de partição sangue:gás ser menor, bem como sua solubilidade em tecido adiposo, o que leva a uma menor depressão da contratilidade miocárdica e a menor vasodilatação cerebral (Maddison et al., 2010).

\section{Corticoides}

\section{Fluticasona}

A fluticasona por via inalatória é usada principalmente para doenças brônquicas onde o animal manifesta tosse crônica (Silva et al., 2017). Nesses casos, pode-se associá-la com o salmeterol, duas vezes ao dia. No entanto, é válido lembrar que o uso de antibióticos não pode ser feito durante esse período, pois a sensibilidade da fluticasona pode ser alterada. O salbutamol pode ser feito conjuntamente nos momentos de dificuldade respiratória, a cada 4 horas (Feldman, 1997).

Para o efeito completo da fluticasona é necessário uma a duas semanas de tratamento, sendo administrado duas vezes ao dia, iniciando com uma dose para gatos de $110 \mu \mathrm{g}$ (Padrid, 2006). Todavia, de acordo com estudos feitos por Papich (2012), quando as doses foram comparadas experimentalmente em gatos, a dose de $44 \mu \mathrm{g}, 2$ vezes ao dia, foi tão eficaz quanto 110 ou $220 \mu \mathrm{g}, 2$ vezes ao dia. Portanto, recomendam-se começar com $44 \mu \mathrm{g}$ por dose (uma aspiração por inalador de $44 \mu \mathrm{g}$ ) 2 vezes ao dia e aumentar a dose, se necessário, para $110 \mu \mathrm{g}$, ou então para $220 \mu \mathrm{g}$. Além disso, é necessário um inalador com dosímetro em 44, 110 ou $220 \mu \mathrm{g}$ por inalação (Papich, 2012). Por fim, dado que estas formulações demoram uma a duas semanas para atingir o seu efeito máximo, está indicada a administração concomitante de prednisolona (corticosteroides) durante este período de tempo, seguindo-se o desmame da fórmula oral e manutenção da fórmula inalatória apenas (Jericó et al., 2015; Nelson \& Couto, 2015).

\section{Salbutamol}

O salbutamol é usado pela via inalatória por meio do auxílio de nebulizadores. Seu efeito se inicia em até 10 minutos, podendo durar até quatro horas (Decian, 2019). Pode ser aplicado a cada 12 ou 24 horas por inalação e, se associado a Fluticasona, deve ser administrado antes (De Lorenzi et al., 2009; Little, 2016). Além disso, segundo Decian (2019), esse fármaco deve ser empregado apenas quando o animal apresentar sintomas respiratórios, uma vez que o uso prolongado pode desenvolver processos inflamatórios (Jericó et al., 2015; Reinero et al., 2020; Venema et al., 2010). Além disso, o tratamento de doenças do sistema respiratório como bronquite crônica e asma felina é facilitado por essa via de administração, por meio do uso de bombinhas, sprays nasais ou com o uso da nebulização (Spinosa et al., 2017). 


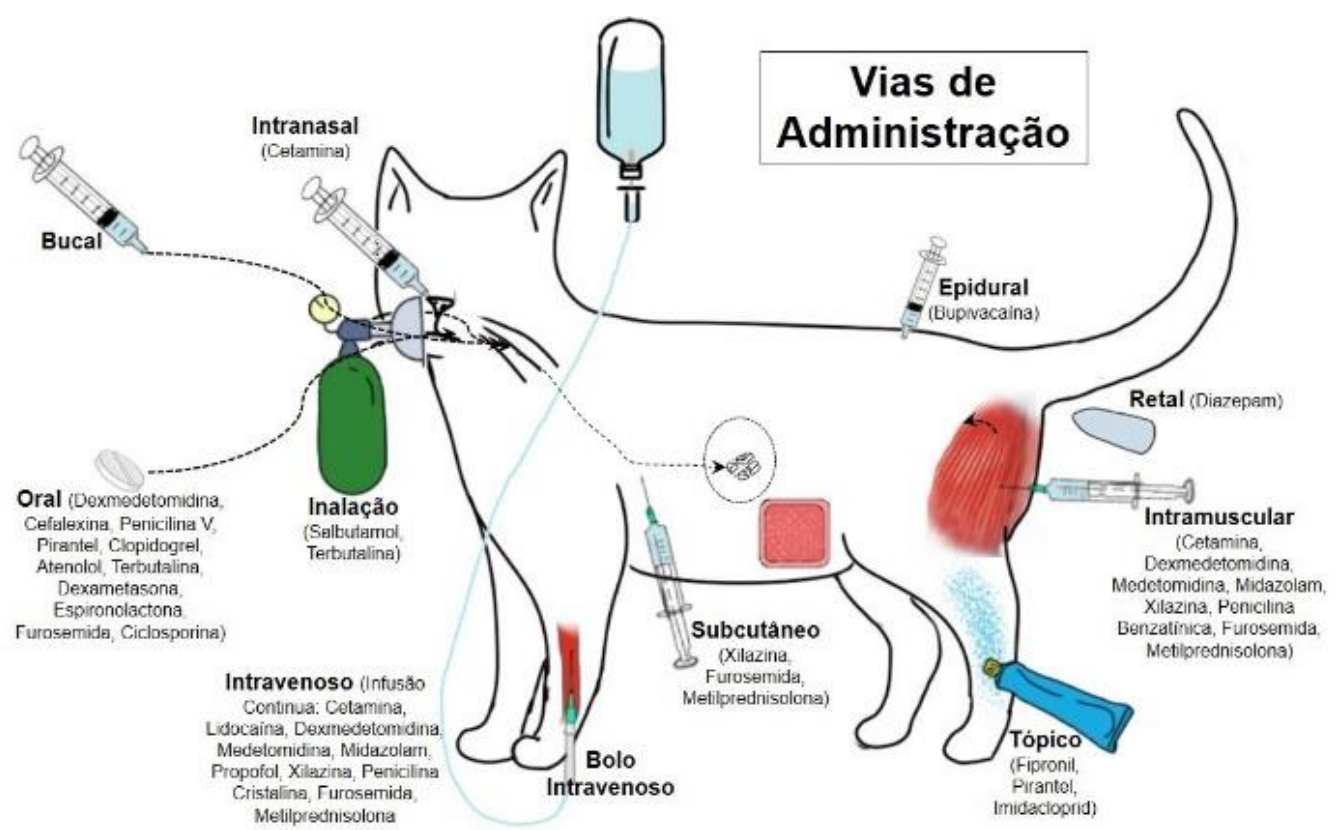

Figura 7. Vias de administração utilizadas em gatos e os principais fármacos utilizados.

\section{Considerações finais}

Fica evidente que as vias de administração, são divididas em duas classes: enterais e parenterais, o que reflete na sua biodisponibilidade e tempo de latência de um fármaco. Esses fatores por sua vez, têm impacto direto sobre o efeito do fármaco, assim como as doses administradas e a facilidade no manejo terapêutico. Por isso, conhecer as particularidades da medicina felina, bem como dos processos farmacocinéticos e farmacodinâmicos envolvidos, influencia tanto na escolha dos protocolos recomendados, quanto na eficácia desses tratamentos. Portanto, é de suma importância que os médicos veterinários conheçam essas características e instruam os tutores a não medicarem seus animais sem uma orientação prévia, demonstrando os efeitos adversos e possíveis intoxicações que podem ser gerados caso haja extrapolação de uma via para outra.

Por fim, cabe salientar que o bem-estar do animal também deve ser uma prioridade, devendo sempre ser levado em consideração. Isso significa que, caso uma via possa ser substituída por outra menos estressante, (por exemplo, via oral por subcutânea) essa troca deve ser considerada desde que mantenha a eficácia do tratamento, analisando sempre seus benefícios uma vez que o estresse pode levar a problemas ainda mais graves.

\section{Referências bibliográficas}

Aleixo, G. A. S., \& Tudury, E. A. (2007). Utilização de opióides na analgesia de cães e gatos. Veterinária Notícias, 11(2), 31-42.

Aragão, J. (2012). Guia Brasileiro de Boas Práticas em Eutanásia em Animais - Conceitos e Procedimentos Recomendados (Issue 1, p. 62 p.). CRMV.

Arias, M. V. B., Battaglia, L. A., Aiello, G., Carvalho, T. T., \& Freitas, J. C. (2008). Identificação da suscetibilidade antimicrobiana de bactérias isoladas de cães e gatos com feridas traumáticas contaminadas e infectadas. Semina: Ciências Agrárias, 29(4), 861-874. https://doi.org/10.5433/1679-0359.2008v29n4p861.

Bauer, K. P., Dom, P. M., Ramirez, A. M., \& O’Flaherty, J. E. (2004). Preoperative intravenous midazolam: benefits beyond anxiolysis. Journal of ClCnical Anesthesia, 16(3), 177-183. https://doi.org/10.1016/j.jclinane.2003.07.003.

Bergman, P. J. (2003), Mechanisms of anticancer drug resistance. Veterinary Clinics: Small Animal Practice, v. 33, n. 3, p. 651-667, 2003. doi:10.1016/s0195-5616(03)00004-4

Biesalski, H. K. (2001). Evidence from intervention studies. Bibliotheca Nutritio et Dieta, 55(55), 92-134.

Bonagura, J. D., \& Kirk, R. W. (1992). Current veterinary therapy: small animal practice (Vol. 13). 
WB Saunders.

Booth, N. H., \& McDonaldo, L. E. (1992). Farmacologia e terapêutica em veterinária. Guanabara Koogan.

Boothe, D. M. (2011). Small Animal Clinical Pharmacology and Therapeutics-E-Book. Elsevier Health Sciences.

Bortoli, A. W., \& Ribeiro, R. N. (2019). Avaliação de sedação por via oral transmucosa em gatos (felis catus) pela associação de dexmedetomidina e dextrocetamina. Arquivos Brasileiros de Medicina Veterinária, 2(1), 121-128.

Bressan, T. F. (2017). Localização dos receptores opioides no sistema nervoso central e avaliação dos efeitos analgésico e sedativo da morfina e butorfanol em iguanas verdes (Iguana iguana). Universidade de São Paulo.

Campagnol, D. (2011). Farmacologia clínica da metadona peridural e intravenosa em cães. Universidade Estadual Paulista (UNESP).

Campos, D. B., Garibaldi, I. M., \& Carneiro, J. R. (1974). Prevalência de helmintos em gatos (Felis catus domesticus) de Goiânia. Revista de Patologia Tropical, 3(4), 355-359.

Campos, D. R., Ouza, H. J. M., \& Carrasco, L. P. S. (2015). Verminoses em gatos. Boletim Bayer Vet, 2(7), 1-8.

Capuano, D. M., \& Rocha, G. M. (2006). Ocorrência de parasitas com potencial zoonótico em fezes de cães coletadas em áreas públicas do município de Ribeirão Preto, SP, Brasil. Revista Brasileira de Epidemiologia, 9(1), 81-86.

Carregaro, A. B., Neto, L. R. M., \& Lima, R. R. (2004). Padronização invasiva da pressão arterial auricular caudal em cães submetidos à anestesia inalatória. Brazilian Journal of Veterinary Research and Animal Science, 41, 51-52.

Carvalho, V. L. A. B. (2009). Hipertensão arterial felina. In Faculdade de Medicina e Veterinária: Vol. Master. Universidade Técnica de Lisboa.

Castro-Janer, E., Martins, J. R., Mendes, M. C., Namindome, A., Klafke, G. M., \& Schumaker, T. T. S. (2010). Diagnoses of fipronil resistance in Brazilian cattle ticks (Rhipicephalus (Boophilus) microplus) using in vitro larval bioassays. Veterinary Parasitology, 173(3-4), 300-306.

Cubas, Z. S., Silva, J. C. R., \& Dias, J. L. C. (2014). Tratado de animais selvagens-medicina veterinária. Editora Roca.

De Lorenzi, D., Bertoncello, D., \& Drigo, M. (2009). Bronchial abnormalities found in a consecutive series of 40 brachycephalic dogs. Journal of the American Veterinary Medical Association, 235(7), 835-840.

Decian, A. (2019). Asma e bronquite crônica em gatos domésticos.

Domingos, T. C. S., Rocha, A. A., \& Cunha, I. C. N. (2008). Cuidados básicos com a gestante e o neonato canino e felino: revisão de literatura. Jornal Brasileiro de Ciência Animal, 1(2), 94-120.

Emilio, C. R., Osório, D. D. P., Mariano, A. P., Luna, S. P. L., Gonçalves, R. C., Mannarino, R., \& Foloni, V. S. (2004). Efeito da ioimbina como antagonista da xilazina em cães e gatos. Acta Scientiae Veterinariae, 32(1), 53-57. https://doi.org/10.22456/1679-9216.16803.

Ettinger, S. J., Fedlman, E. C., \& Taibo, R. A. (2002). Tratado de medicina interna veterinaria: enfermedades del perro y el gato. Manole.

Fantoni, D. T., \& Cortopassi, S. R. G. (2009). Anestesia em cães e gatos. Roca.

Farias, N. A., Christóvão, M. L., \& Stobbe, N. S. (1995). Frequiência de parasitas intestinais em cães (Canis familiaris) e gatos (felis catus domestica) em Araçatuba, São Paulo. Revista Brasileira de Parasitologia Veterinária, 4, 57-60.

Feldman, E. C. (1997). Tratado de medicina interna veterinária. In Moléstias do cão e do gato (Vol. 3).

Ferreira, G. S., Masson, G. C. I. H., Galvao, A. L. B., Palazzo, E. L., \& Pinto, M. L. (2011). Vírus da imunodeficiência felina: um desafio clínico. Nucleus Animalium, 3(1), 85-98.

Ferreira, S. T., \& Zimmermann, M. (2017). Cuidados básicos com a gestante e o neonato felino. Revista Científica de Medicina Veterinária Do UNICEPLAC, 4(1), 58-71. https://doi.org/10.51161/rems/1935.

Ferreira, T. H., Rezende, M. L., Mama, K. R., Hudachek, S. F., \& Aguiar, A. J. A. (2011). Plasma concentrations and behavioral, antinociceptive, and physiologic effects of methadone after intravenous and oral transmucosal administration in cats. American Journal of Veterinary Research, 72(6), 764-771. 
Ferreira, W. L., Aylon, E. G., \& Carregaro, A. B. (2006). Ação antiarrítmica do isofluorano em cães submetidos a arritmias ventriculares induzidas por cloreto de bário. Arquivo Brasileiro de Medicina Veterinária e Zootecnia, 58(6), 1064-1069.

Fighera, R. A., Souza, T. M., Silva, M. C., Brum, J. S., Graça, D. L., Kommers, G. D., Irigoyen, L. F., \& Barros, C. S. L. (2008). Causas de morte e razões para eutanásia de cães da Mesorregião do Centro Ocidental Rio-Grandense (1965-2004). Pesquisa Veterinária Brasileira, 28(4), 223-230. https://doi.org/10.1590/s0100-736x2008000400005.

Figueiredo, A. C. C., \& Araújo, F. A. A. (2001). Eutanásia animal em centros de controle de zoonoses. Revista Do Conselho Federal de Medicina Veterinária, 23, 12-17.

Fiorini, E. A., Siragusi, R. H. S., Junior, E. A. L., \& Franco, R. P. (2017). Utilização da furosemida em bolus e em infusão contínua em cães e gatos: revisão de literatura. Revista de Educação Continuada Em Medicina Veterinária e Zootecnia Do CRMV-SP, 15(1), 54-60. https://doi.org/10.36440/recmvz.v15i1.36768.

Ford, R. B., \& Mazzaferro, E. (2013). Kirk \& Bistner's Manual de procedimentos veterinários e tratamentos de emergência. Elsevier Brasil.

Fraser, C. M., Bergeron, J. A., Mays, A., \& Aiello, S. A. (1996). Manual Merck de Veterinária: um manual de diagnóstico, tratamento, prevenção e controle de doenças para o veterinário. Roca.

Greene, C. E., Samperio, J. O., \& Gómez, J. P. (1993). Enfermedades infecciosas: Perros y gatos. Editora Interamericana.

Gremião, I. D. F., Menezes, R. C., Schubach, T. M. P., Figueiredo, A. B. F., Cavalcanti, M. C. H., \& Pereira, S. A. (2015). Feline sporotrichosis: epidemiological and clinical aspects. Medical Mycology, 53(1), 15-21. https://doi.org/10.1093/mmy/myu061.

Hartmann, K., \& Baneth, G. (2006). Infectious diseases of the dog and cat. In C. E. Greene (Ed.), Hepatozzon canis Infection (3a ed., Vol. 1). Elsevier Health Sciences.

Henik, R. A., Stepien, R. L., Wenholz, L. J., \& Dolson, M. K. (2008). Efficacy of atenolol as a single antihypertensive agent in hyperthyroid cats. Journal of Feline Medicine and Surgery, 10(6), 577582. https://doi.org/10.1016/j.jfms.2007.11.008.

Huang, J., Wang, W., Yu, J., Yu, X., Zheng, Q., Peng, F., He, Z., Zhao, W., Zhang, Z., \& Li, X. (2017). Combination of dexamethasone and Avastin ${ }^{\circledR}$ by supramolecular hydrogel attenuates the inflammatory corneal neovascularization in rat alkali burn model. Colloids and Surfaces B: Biointerfaces, 159, 241-250. https://doi.org/10.1016/j.colsurfb.2017.07.05.

Jericó, M. M., Kogika, M. M., \& Andrade Neto, J. P. (2015). Tratado de medicina interna de cães e gatos. Guanabara Koogan.

Juraski, A., Simbara, M., Paschon, V., Malmonge, S., \& Daguano, J. (2017). Ibuprofen loaded chitosan films: in vitro assessment of drug release profile and cell viability on primary neurons culture. Iranian Journal of Materials Science and Engineering, 1, 1-15.

Lignon, J. S., Antunes, T. Á., Padilha, V. M., Ritta, M. D., Dantas, H. M., \& Pinto, D. M. (2019). Diagnóstico de Taenia taeniaeformis (Cyclophyllidea: Taeniidae) em felino doméstico em Pelotas, RS: relato de caso. PUBVET, 13(10), 1-4. https://doi.org/10.31533/pubvet.v13n10a436.1-4.

Little, S. E. (2016). O gato: medicina interna. Editora Roca.

Lopes, R. C., Bondan, E. F., \& Stevanin, H. (2019). Estudo comparativo na cicatrização de mastectomias em cadelas utilizando Regepil, gentamicina e rifamicina. Revista Veterinária de Cãs e Gatos, 35(235), 68-70.

Maddison, J. E., Page, S. W., \& Church, D. B. (2010). Farmacologia clínica em pequenos animais. Elsevier Brasil.

Magalhães, E., Govêia, C. S., \& Oliveira, K. B. (2004). Bupivacaína racêmica, levobupivacaína e ropivacaína em anestesia loco-regional para oftalmologia - um estudo comparativo. Revista Sociedade Médica Brasileira, 50(2), 195-198.

Marco, V., Winkel, V. M., \& Martorelli, C. R. (2012). Estudo da hipercoagulabilidade sanguínea em 45 cães com hiperadrenocorticismo endógeno, por meio da avaliação da frequência de trombocitose, hiperfibrinogenemia e hipertensão arterial. Clínica Veterinária, 17(96), 44-50.

Marjani, M., Akbarinejad, V., \& Bagheri, M. (2015). Comparison of intranasal and intramuscular 
ketamine-midazolam combination in cats. Veterinary Anaesthesia and Analgesia, 42(2), 178-181. https://doi.org/10.1111/vaa.12183.

Massone, F. (2017). Anestesiologia veterinária. In Farmacologia e técnicas. Guanabara Koogan.

McKelvey, D., \& Hollingshead, K. W. (1994). Small animal anesthesia: canine and feline practice. Mosby.

McMichael, M. A. (2011). Emergência eqQuestões relacionadas ao cuidado intensivo. In M. E. Peterson \& M. A. Kutzler (Eds.), Pediatria em pequenos animais (pp. 1-73). Elservier.

Moreira, R. H. (2009). Hiperadrenocorticismo iatrogênico em cão: relato de caso. Revista Científica Eletrônica de Medicina Veterinária, 2(3), 1.

Nelson, R. W., \& Couto, C. G. (2015). Medicina interna de pequenos animais (Issue 1). Elsevier Editora.

Ozanam, F. (2007). Abordagem terapêutica do paciente neonato canino e felino: 2. Aspectos relacionados a terapia intensiva, antiparasitários e antibióticos.

Padrid, P. (2006). Use of inhaled medications to treat respiratory diseases in dogs and cats. Journal of the American Animal Hospital Association, 42(2), 165-169. https://doi.org/10.5326/0420165.

Panontin, J. F., \& Oliveira, J. R. S. (2017). Formulações magistrais veterinárias tópicas e de via oral para o tratamento de alergias em cães. Revista Cientifica de Medicina Veterinária, 1(28), 1-14.

Papich, M. G. (2012). Manual Saunders de Terapia Veterinária. Elsevier Health Sciences Brazil.

Peixoto, G. C. X., \& Bezerra Junior, R. Q. (2010). Cuidados básicos com o neonato canino: uma revisão. PUBVET, 4, 717-722.

Pereira, D., Fernandes, S., Silva, N., \& Silva, T. (2006). Infusão intra-óssea na emergência clínica veterinária - relato de caso. Veterinária Noticias, 12(2).

Pereira, J. R. (2011). Práticas de controle e prevalência de helmintos gastrintestinais parasitos de bovinos leiteiros em Pindamonhangaba, São Paulo, Brasil. Revista de Ciências Agroveterinárias, 10(1), 16-22.

Plumb, D. C. (2018). Plumb's veterinary drug handbook: Desk. John Wiley \& Sons.

Poffo, D. (2012). Infecção pelo vírus da imunodeficiência viral felina e leucemia viral em felídeos domésticos e silvestres atendidos no Hospital Veterinário da UFMT- Cuiabá- Brasil. In Clínica Médica, Cirúrgica e Apoio diagnóstico em Medicina Veterinária de pequenos animais: Vol. Graduate. Universidade Federal de mato Grosso do Sul.

Polydoro, A. S., Natalini, C. C., Raiser, A. G., \& Hennemanin, C. R. A. (2006). Analgesia e anestesia epidural em cães e gatos: revisão de literatura. A Hora Veterinária, 25(149), 31-37.

Porters, N., De Rooster, H., Bosmans, T., Baert, K., Cherlet, M., Croubels, S., Backer, P., \& Polis, I. (2015). Pharmacokinetics of oral transmucosal and intramuscular dexmedetomidine combined with buprenorphine in cats. Journal of Veterinary Pharmacology and Therapeutics, 38(2), 203-208. https://doi.org/10.1111/jvp.12172.

Pulz, R. S., Kosachenco, B., Bagathini, S., Silveira, R. S., Menegotto, G. N., \& Cristina Schneider, B. C. (2011). A eutanásia no exercício da medicina veterinária: aspectos psicológicos. Revista Veterinária Em Foco, 9(1), 88-94.

Ramalhais, A., \& Ribeiro, R. N. (2020). Avaliação da sedação por via intranasal em gatos domésticos (felis catus) pela administração de dexmedetomidina. Arquivos Brasileiros de Medicina Veterinária FAG, 3(1), 18-29.

Razal, N. S., Rodriguez, P. V. F. H., Santos Filho, M., \& Freitas, R. A. (2020). Polimiopatia hipocalêmica e hipertensão secundária a hiperaldosteronismo primário felino. Revista Brasileira de Ciência Veterinária, 27(2), 65-70. https://doi.org/10.4322/rbcv.2020.013.

Reinero, C., Visser, L. C., Kellihan, H. B., Masseau, I., Rozanski, E., Clercx, C., Williams, K., Abbott, J., Borgarelli, M., \& Scansen, B. A. (2020). ACVIM consensus statement guidelines for the diagnosis, classification, treatment, and monitoring of pulmonary hypertension in dogs. Journal of Veterinary Internal Medicine, 34(2), 549-573. https://doi.org/10.1111/jvim.15725.

Reis, É. G., Schubach, T. M. P., Pereira, S. A., Silva, J. N., Carvalho, B. W., Quintana, M. S. B., \& Gremião, I. D. F. (2016). Association of itraconazole and potassium iodide in the treatment of feline sporotrichosis: a prospective study. Medical Mycology, 54(7), 684-690. https://doi.org/10.1093/mmy/myw027.

Reis, J. (2015). Protocolos Clínicos-Diagnóstico e intervenção em clínica de animais de companhia. Universidade de Évora-disponibilizado via Moodle. 
Riviere, J. E., \& Papich, M. G. (2018). Veterinary pharmacology and therapeutics. John Wiley \& Sons. Rosa, V. M., Carniato, C. H. O., \& Campanerutti, G. (2011). Hiperadrenocorticismo em cães. In Encontro Internacional de Produção Científica. CESUMAR.

Rozanski, E. A., \& Rush, J. E. (2009). Manual colorido de medicina de urgência e terapia intensiva em pequenos animais. Artes Médicas.

Saba, C. F. (2017). Vaccine-associated feline sarcoma: current perspectives. Veterinary Medicine: Research and Reports, 8, 13. https://doi.org/10.2147/VMRR.S116556.

Sandem, A. I., Janczak, A. M., Salte, R., \& Braastad, B. O. (2006). The use of diazepam as a pharmacological validation of eye white as an indicator of emotional state in dairy cows. Applied Animal Behaviour Science, 96(3-4), 177-183. https://doi.org/http://dx.doi.org/10.1016/j.applanim.2005.06.008

Santos, I. C., Sousa, R. V, \& Santana, G. C. (2006). Princípios da antibioticoterapia em medicina veterinária. Boletim Agropecuário, Lavras, 38, 1-38.

Santos, L. A. C., \& Montanha, F. P. (2011). Eutanásia: Morte Humanitária. Revista Científica Eletrônica de Medicina Veterinária, 1, 1-17.

Santos, L. C. P., Ludders, J. W., Erb, H. N., Basher, K. L., Kirch, P., \& Gleed, R. D. (2010). Sedative and cardiorespiratory effects of dexmedetomidine and buprenorphine administered to cats via oral transmucosal or intramuscular routes. Veterinary Anaesthesia and Analgesia, 37(5), 417-424. https://doi.org/10.1111/j.1467-2995.2010.00555.x.

Sarasola, P., Jernigan, A. D., Walker, D. K., Castledine, J., Smith, D. G., \& Rowan, T. G. (2002). Pharmacokinetics of selamectin following intravenous, oral and topical administration in cats and dogs. Journal of Veterinary Pharmacology and Therapeutics, 25(4), 265-272. https://doi.org/10.1046/j.1365-2885.2002.00415.x.

Savola, J. M. (1989). Cardiovascular actions of medetomidine and their reversal by atipamezole. Acta Veterinaria Scandinavica. Supplementum, 85, 39-47.

Seli, K. A., Ana, R., Kamaja, O., \& Butinar, J. (2005). Intra-e efeitos analgésico pós-operatórios de carprofen em medetomidine premedicated dogs que sofre ovariectomy. Acta Veterinária (Beograd), v.55, n.5-6, p.435-448, 2005. Acta Veterinariae, 55(5-6), 435-448.

Short, J., \& Gram, D. (2016). Successful treatment of Demodex gatoi with 10\% imidacloprid/1\% moxidectin. Journal of the American Animal Hospital Association, 52(1), 68-72.

Silva, A. P., Assis, P., Viana, F. A., \& Amaral, A. V. (2015). Flap de terceira pálpebra para tratamento de úlcera de córnea colagenolítica difusa em cão: relato de caso. Enciclopédia Bioesfera, 11(22), 1296-1305. https://doi.org/10.18677/enciclopedia_biosfera_2015_160.

Silva, B. R. S. A., Santos Filho, M., Soares, D. V., Mattos, R. G. M. R. B., Suzano, S. M. de C., \& Paiva, J. P. (2017). Obstrução de via aérea superior secundária a cisto epidermóide laringiano em gato: relato de caso. Brazilian Journal of Veterinary Medicine, 39(1), 74-81.

Site, H. G. (2006). Clopidogrel plus aspirin versus oral anticoagulation for atrial fibrillation in the Atrial fibrillation Clopidogrel Trial with Irbesartan for prevention of Vascular Events (ACTIVE W): a randomised controlled trial. Lancet, 367(9526), 1903-1912. https://doi.org/10.1016/S0140-6736(06)68845-4.

Smith, S. A., Tobias, A. H., Jacob, K. A., Fine, D. M., \& Grumbles, P. L. (2003). Arterial thromboembolism in cats: acute crisis in 127 cases (1992-2001) and long-term management with low-dose aspirin in 24 cases. Journal of Veterinary Internal Medicine, 17(1), 73-83. https://doi.org/10.1892/0891-6640(2003)017<0073:ATICAC>2.3.CO;2.

Sobeck, U., Fischer, A., \& Biesalski, H. K. (2003). Uptake of vitamin A in buccal mucosal cells after topical application of retinyl palmitate: A randomised, placebo-controlled and double-blind trial. British Journal of Nutrition, 90(1), 69-74. https://doi.org/10.1079/BJN2003854

Spinosa, H. S. de S., Górniak, S. L., \& Bernardi, M. M. (2017). Farmacologia aplicada à medicina veterinária. Koogan Guanabara.

Surendar, M. N., Pandey, R. K., Aksena, A. S., Kumar, R., \& Chandra, G. (2014). A comparative evaluation of intrnasal dexmedetomidine, midazolam and ketamine for their sedative and analgesic properties: a triple blind randomized study. Journal of Clinical Pediatric Dentistry, 38(3), 255-261. 
https://doi.org/0.17796/jcpd.38.3.1828585807482966.

Tebaldi, M., Henrique Araújo Machado, L., \& Lucia Gomes Lourenço, M. (2015). Pressão arterial em cães: uma revisão. Periódicos Brasileiros Em Medicina Veterinária e Zootecnia, 22, 198-208.

Tesserolli, G. L., Fayzano, L., \& Agottani, J. V. B. (2005). Ocorrência de parasitas gastrintestinais em fezes de cães e gatos, Curitiba-PR. Revista Acadêmica, 3(4), 31-34.

Vainio, O. (1989). Introduction to the clinical pharmacology of medetomidine. Acta Veterinaria Scandinavica. Supplementum, 85, 85-88.

Valadão, C. A. A. (2010). Anestésicos dissociativos. In: Fantoni, D. T.; Cortopassi, S.R.G. Anestesia de cães e gatos. 2a ed. São Paulo: Roca, p237 -245

Vale, B. N. V, \& Sousa, G. C. M. S. (2018). Vias de administração de drogas e influencia do pH na duração do efeito anestésico do tiopental em roedores. IV SICTEG-Semana Integrada de Ciência e Tecnologia de Gurupi.

Venema, C., Patterson, C., \& Venema, C. M. (2010). Feline asthma: what's new and where might clinical practice be heading? Journal of Feline Medicine and Surgery, 12(9), 681-692.

Viega, I. O. (2018). Ceratectomia lamelar com recobrimento de terceira pálpebra no tratamento de sequestro corneal - relato de caso (p. 33 p.). Centro de Ciências Agrária, Universidade Federal da Paraíba.

Virtanen, R., \& MacDonald, E. (1985). Comparison of the effects of detomidine and xylazine on some $\alpha 2$-adrenoceptor-mediated responses in the central and peripheral nervous systems. European Journal of Pharmacology, 115(2-3), 277-284. https://doi.org/0.1016/0014-2999(85)90700-9.

Ximenes, P. A., Rodrigues, R., Medeiros, V. B., Bezerra, J. A. B., \& Filgueira, K. D. (2018). Uso da quimioterapia intralesional no tratamento do carcinoma de células escamosas cutâneo felino. Revista de Educação Continuada Em Dermatologia e Alergologia Veterinária, 5(14), 66-75.

\section{Histórico do artigo:}

Recebido: 4 de setembro de 2021

Aprovado: 14 de outubro de 2021

Disponível online: 23 de dezembro de 2021
Licenciamento: Este artigo é publicado na modalidade Acesso Aberto sob a licença Creative Commons Atribuição 4.0 (CC-BY 4.0), a qual permite uso irrestrito, distribuição, reprodução em qualquer meio, desde que o autor e a fonte sejam devidamente creditados 